\title{
Formando autores na licenciatura em Química: uma pesquisa-ação no Norte Fluminense
}

\author{
Clevi Elena Rapkiewicz ${ }^{1}$ \\ Valesca de Cezaro ${ }^{2}$ \\ Valéria Machado da Costa $^{3}$ \\ Núbia dos Santos Rosa Santana dos Santos ${ }^{4}$
}

\begin{abstract}
Resumo. Entre as potencialidades das Tecnologias de Informação $e$ Comunicação (TIC) está a autoria. No entanto, esse potencial podes ser limitado pela exclusão digital de muitos professores, mesmo entre os nativos digitais. Este artigo relata a dificuldade e ao mesmo tempo a viabilidade de formar professores produtores de conteúdo a partir de uma pesquisa-ação junto a um grupo de licenciandos em Química. Experiências práticas deles junto a alunos de ensino médio mostrou que a superação das dificuldades de inclusão digital de licenciandos contribui para o empenho destes na produção de conteúdo próprio aproveitando melhor o potencial de autoria das TIC.
\end{abstract}

Palavras-chave: autoria; formação de professores; tecnologias da informação e comunicação, licenciatura em Química

\begin{abstract}
Among the potential of Information and Communication Technology (ICT) is authorship. However, this potential can be limited by digital exclusion of many teachers, even among the digital natives. This article reports on the difficulty and at the same time the feasibility of forming teachers producers of content from an action research along the a group of undergraduates in Chemistry. Practical experiences with them to high school students showed that overcoming the difficulties of digital inclusion of undergraduates contribute to these efforts in producing their own content leveraging the full potential of authorship ICT.
\end{abstract}

Keywords: authorship; teacher training; information and communication technology; degree in Chemistry

\footnotetext{
${ }^{1}$ Pead - Pedagogia a Distância/Faculdade de Educação/UFRGS. Email: clevirap@ gmail.com

${ }^{2}$ Escola Municipal Angelo Chiele - Farroupilha - RS. Email: emac@terra.com.br

${ }^{3}$ PGIE - Programa de Pós-graduação em Informática na Educação - UFRGS Email: costavm@ gmail.com

${ }^{4}$ PGIE - Programa de Pós-graduação em Informática na Educação - UFRGS Email: nubrosa@ gmail.com
} 


\section{Introdução}

Na Era da Informação, o uso de Tecnologias da Informação e Comunicação (TIC) é fundamental para a inclusão digital e social do indivíduo. Mattos (2003) destaca que o acesso às informações e a capacidade de transformar informações em conhecimento são fatores decisivos de inclusão social. Incluir digitalmente é mais do que o acesso à informação. De acordo com Fagundes (2004), a "inclusão digital não é só o amplo acesso à tecnologia, mas a apropriação dela na resolução de problemas".

Um dos problemas vivenciados por professores, em diversas áreas do conhecimento, refere-se à disponibilidade de material digital para uso nas aulas. Apesar da proliferação constante de materiais hipertextuais na Internet e da distribuição de objetos de aprendizagem em repositórios, muitos professores poderiam (ou pretenderiam) desenvolver seus próprios materiais ou, pelo menos, fazer adaptações em materiais já existentes. Para que possam fazer isso, no entanto, é necessário que tenham fluência digital, isto é, não basta saber usar ferramentas tecnológicas, é preciso também saber construir coisas significativas com elas (PAPERT E RESNICK, 1995).

Em princípio, considerando-se a faixa etária dos alunos das licenciaturas (salvo aqueles que voltam a estudar depois de alguns anos fora da universidade, que tem idade diferenciada), seria de se esperar que nos cursos de formação inicial de professores a fluência digital não fosse um problema: esperar-se-ia mais nativos digitais do que imigrantes nesses cursos, nos dizeres de Prensky (2001). Isto é, em princípio o público de cursos de licenciatura teria, entre seus alunos, sobretudo jovens que cresceram com a evolução da Web e das TICs de forma geral, convivendo no dia a dia com artefatos tecnológicos como jogos eletrônicos, celulares, entre outros.

Nesse contexto este artigo analisa o processo de formação de autores entre licenciandos em Química na Universidade Estadual do Norte Fluminense (UENF), localizada na cidade de Campos dos Goytacazes, no estado do Rio de Janeiro, conforme a construção do objeto de pesquisa apresentada na próxima seção. O referencial teórico que balizou o projeto encontra-se sintetizado na seção 3. Os resultados são apresentados na seção 4 e algumas considerações finais são delineadas na seção 5.

\section{Construção do objeto de pesquisa}

O contexto no qual foi desenvolvido o projeto de pesquisa foi o de busca de formação de autores entre licenciandos em Química para que pudessem ser autores de seu próprio material didático ou reutilizassem de forma adaptada materiais já existentes, aproveitando melhor as TICs atuais. O cenário é favorável à mudança de papel do professor uma vez que é cada vez maior o número de ferramentas gratuitas e de interface amigável que podem ser utilizadas por professores com pouco conhecimento em informática. Tais ferramentas compõem o que Anderson (2006) chama de primeira força da Cauda Longa, isto é, a democratização dos meios de produção permite que usuários com poucos conhecimentos de TIC produzam conteúdos de qualidade e esteticamente agradáveis. Além disso, cada vez 
mais ferramentas permitem a colaboração entre os usuários, ampliando as trocas entre os ditos "especialistas" e os "amadores".

A pergunta que guiou a pesquisa feita foi: quais os limites e possibilidades para formação de autores entre licenciandos em Química na UENF considerando-se as características de fluência digital dos mesmos?

A hipótese associada a este objetivo é que o fato dos alunos do curso em questão serem nativos digitais facilita o processo de formação dos mesmos para autoria, uma vez que os mesmos reuniriam as facilidades para manipulação de ferramentas, permitindo assim explorar as potencialidades das TICs atuais para que sejam também produtores e não apenas consumidores de conteúdo.

A metodologia usada foi a pesquisa-ação. A pesquisa-ação, método qualitativo particular de pesquisa social, enfatiza especificidades, onde o pesquisador detecta um problema em seu meio, buscando estratégias de ação para modificar a situação identificada. Favorece as discussões e a produção cooperativa de conhecimentos específicos sobre a realidade vivida, com foco principal na análise das práticas instituídas no convívio social. Para Thiollent (2007) pesquisa-ação é:

[...] um tipo de pesquisa social com base empírica que é concebida e realizada em estreita associação com uma ação ou com a resolução de um problema coletivo e no qual os pesquisadores e os participantes representativos da situação ou do problema estão envolvidos de modo cooperativo ou participativo. (THIOLLENT, 2007, p. 16).

O problema coletivo a ser resolvido com o grupo foco do projeto era aproveitar o potencial de seus integrantes para autoria dotando-os de condições de usar ferramentas para desenvolver seu próprio conteúdo digital. O envolvimento dos integrantes ocorreu de modo participativo na medida em que o planejamento das oficinas com as ferramentas para autoria ministradas para os licenciandos ocorreu a partir de dinâmicas negociadas com eles e de forma cooperativa na medida em que durante as oficinas foram estimuladas criações individuais para integrar material digital coletivo de cada grupo.

Atualmente muito aplicada na área da educação, a pesquisa-ação serve para elaborar uma análise de uma realidade em que o pesquisador está envolvido, unindo a ação à prática. Pode-se apontar uma de suas vantagens na possibilidade de intervir e colocar em prática uma ação inovadora, já no momento que está transcorrendo a pesquisa.

Os dados analisados numa pesquisa-ação são personalizados, restritos e específicos à situação, não podendo ser generalizados, pois somente são válidos ao ambiente estudado. Mesmo tendo limitações, os benefícios da pesquisa-ação estão nos subsídios para a tomada de decisões, sobretudo quando buscam solucionar situações problemáticas. No entanto, melhor do que deixar a problemática no estado em que se encontra, é aplicar soluções imediatas, situações estas que não podem esperar por soluções teóricas. No caso específico desse projeto, a solução prática imediata foi implementar um plano de ação com vistas a instrumentalizar os licenciandos para o exercício da autoria. 


\section{Referencial teórico}

O referencial teórico que balizou o projeto foi organizado em dois eixos: um tecnológico e outro na componente pedagógica do prosumidor.

\section{1 - TIC e autoria}

Um dos elementos que mais caracteriza o potencial atual de autoria das TIC é a Web 2.0. Este termo foi criado em 2004 durante uma seção de brainstorming entre O'Reilly e a MediaLive International. Criticada por alguns e adotado por muitos, o fato é que esse "rótulo" diz respeito a um grande número de sites e ferramentas que priorizam, em maior ou menor grau, a colaboração. De acordo com O’Reilly (2005), a Web 2.0 é uma atitude, não uma tecnologia. Mais do que isso, é uma volta às origens, uma retomada aos princípios da Web.

Quando Vannevar Bush pensou no dispositivo Memex (memory extension) em 1945, seu intuito era a criação de um dispositivo "para mecanizar a classificação e a seleção por associação paralelamente ao princípio da indexação clássica" (LÉVY, 1993, p. 28). Sendo assim, permitir que as pessoas possam, além de ler, escrever, alterar, contribuir, não pode ser considerado uma revolução. No entanto alguma coisa mudou. Se antes os usuários criavam sites pessoais, hoje criam blogs que permitem aos leitores fazerem comentários e, ao "linkar" outros blogs, fazer parte da blogosfera, ou seja, o importante é estar conectado a outros e permitir a opinião dos leitores. Se antes usava-se um sistema gerenciador de conteúdo para publicar informações, hoje se pensa em wikis, em formas colaborativas de produção e edição. Se antes o objetivo era publicar, era ter uma presença na Web, mesmo que fosse um site estático e com uma interface rudimentar, hoje o objetivo é participação. Os autores de espaços na Web querem, e precisam, que seus leitores participem em algum momento do seu site, que se sintam parte do mesmo, um colaborador, numa atitude ativa ao invés de passiva. Essa é a característica essencial da Web 2.0, mas para se chegar a essa colaboração, há um caminho a trilhar para a autoria associada à interação. O caminho a trilhar, proposto no projeto, está ilustrado na Figura 1, mostrando que houve preocupação em utilizar softwares que permitissem diferentes níveis de participação do aluno. 


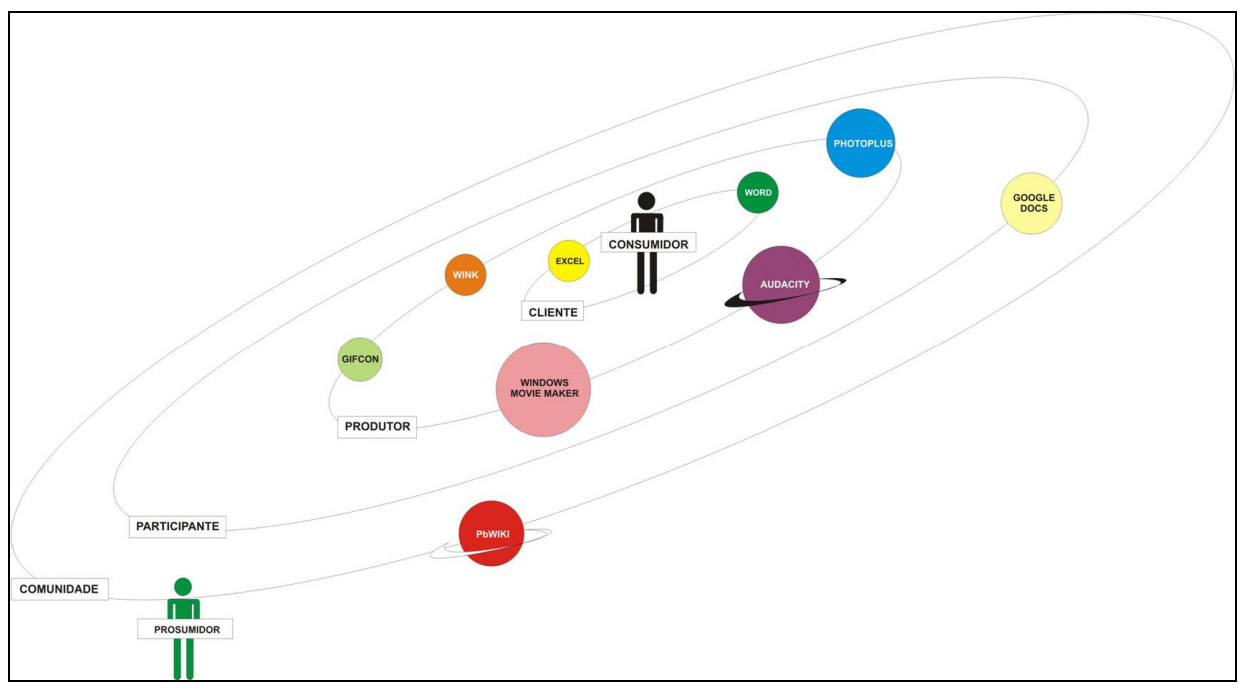

Figura 1- Níveis de participação permitidos pelos softwares

Fonte: autoria própria

No primeiro nível, estão os softwares $^{5}$ que fazem do usuário um cliente (consumidor) das possibilidades já apresentadas pelos mesmos. No segundo nível estão os softwares (Wink, Audacity ${ }^{6}$ etc.) que tornam o usuário produtor de seu próprio conteúdo. Aqui, a mudança de posição do aluno já é significativa, no entanto, tais ferramentas não permitem o compartilhamento e a colaboração entre os estudantes. Estas opções tornam-se viáveis em ferramentas como o Google Docs, que permitem a produção coletiva de textos, apresentações e planilhas.

Por fim, no último nível, estão ferramentas como o Pbwiki $^{7}$ (site para criação de wikis, isto é, permite a criação e edição coletiva de documentos) que, além de permitirem o compartilhamento e a colaboração, criam comunidades, uma vez que permitem que o conteúdo gerado fique disponível na Internet com links para outros sites, gerando a possibilidade de inclusão de novos participantes.

\section{1 - Prosumidor: o que vem a ser?}

O cenário da comunicação mudou de forma radical com a revolução das mídias associada às novas tecnologias. A partir da conectividade com a rede, as pessoas produzem seu próprio conteúdo e conseguem ampliar a capacidade cognitiva e influenciar o comportamento através da web, na medida em que as pessoas se fazem mais presentes na rede.

Esse novo contexto coloca a humanidade no paradigma emergente da complexidade: todos os fenômenos se interrelacionam, as comunicações propiciam a interatividade em tempo real, o mundo transformou-se num espaço de interação.

\footnotetext{
${ }^{5}$ Softwares como Excel e Word permitem o uso de programação, mas é um conhecimento que está fora do campo de experiência da maioria dos alunos e professores.

${ }^{6}$ Software para edição de áudio.

${ }^{7}$ Atualmente chamado de pbworks (http://www.pbworks.com). Na época do projeto ainda era conhecido como Pbwiki.
} 
[...] a complexidade é a união entre a unidade e a multiplicidade. Os desenvolvimentos próprios a nossa era planetária no confrontam cada vez mais e de maneira cada vê mais inelutável com os desafios da complexidade.

Em consequência, a educação deve promover a inteligência geral apta a referir-se ao complexo, ao contexto, de modo multidimensional e dentro da concepção global. (MORIN, 2002, p.38)

No papel relevante que a informação exerce nesse contexto, a informática e a WEB inserem novos conceitos que, avaliando a capacidade do ser humano de interagir com as novas TIC, a elas se integrando, consolidam também a emergência do novo paradigma. Sob esse ponto de vista, Tapscott e Williams (2007, p. 158) reconhecem que os consumidores também são produtores, ou seja, eles são prosumidores.

O conceito de prosumidor é de relevante importância, uma vez que é aceito na produção e no consumo de conhecimentos e aprendizagens. Cumpre registrar que estas potencialidades nasceram da área jornalística, ou seja, da comunicação, onde características automatizadas asseguradas e combinadas com técnicas amadoras incrementaram produções e deram maior acessibilidade e sucesso a estruturas de produções.

O termo prosumidor descreve o fenômeno no qual se constata que o indivíduo não é apenas consumidor de conteúdos, é, ao mesmo tempo, produtor de informação. Parece conflitante o fato de ser produtor e consumidor ao mesmo tempo, mas é possível romper fronteiras e regras convencionais e participar de projetos de criação e produção de forma ativa e colaborativa. Essa expressão, expressão inventada por Alvin Tofler (2007) em seu livro "A Terceira Onda", encontrou uma nova versão no mundo on-line. Trata-se do consumidor que possui mais poder, que emite opiniões, produz informações sobre o que consome e influencia outros consumidores.

Então, em tempos de internet, as mídias possuem uma fórmula cada vez mais alucinante de permitir que o indivíduo habituado a ser receptor da informação, passe também a ser autor, pois possui a capacidade de fornecer informações sobre o que se quer e como quer, ou seja, o prosumidor potencializa a aprendizagem e a colaboração.

Para Tascott e Williams (2007, p.171), "com uma plataforma aberta" e um complemento de ferramentas simples, pessoas comuns podem criar novos e efetivos serviços de informação. Nesta perspectiva e no contexto escolar, os envolvidos não são apenas prosumidores (pessoas comuns), são sujeitos que constroem a partir de desejos e das necessidades dos sujeitos envolvidos, dando maior significado à aprendizagem com produção colaborativa e mediada pelas TIC.

Pode-se aplicar o fenômeno prosumidor ao conceito de criação e montagem, onde a proliferação das ferramentas de autoria, aliadas à massificação dos computadores, faz com que sejam possíveis edições antes somente elaboradas por profissionais com grandes recursos e funcionalidades.

A escola, acima de tudo deve ser o espaço mais propício para que este fenômeno se dê de maneira eficaz. É papel da escola promover, entre os alunos, um envolvimento interativo para produzir e consumir conteúdos, construindo desafios e procurando soluções de problemas. Mas é importante que os alunos não apenas se envolvam na solução de problemas elaborados pelo professor, mas que eles próprios sejam produtores de seu 
próprio conteúdo, garantindo assim que o fazer pedagógico se enquadre nas possibilidades cognitivas e despertem o interesse do educando. Mais do que produzir problemas, o professor precisa mediar ações, "ensejar e urdir múltiplos recursos" (SILVA, 2002) em que os alunos possam construir seus próprios caminhos de conhecimento, o que se aplica aos licenciandos, futuros professores.

O fato de que os alunos participam da elaboração de suas aprendizagens faz com que assumam a função de prosumidor, adquirindo um novo sentido, criando-se um novo aprender, tornando o educar uma estratégia de aprendizagem interessante e eficaz, produzindo saberes significativos e duradouros.

Possibilitar aos alunos que eles se apropriem de ferramentas que facilitam a experimentação, sendo desafiados pelo professor a sempre irem um pouco além, é modo de contextualizar as atividades e, conseqüentemente, as aprendizagens, superando o papel de transmissor e desafiando-os, constantemente, a não só consumir informações, mas, também, a produzi-las.

A facilidade de produção e publicação de conteúdos proporcionada pelas novas ferramentas e a superação da atuação passiva, possibilitam transformar o aluno num colaborador ativo no ciberespaço. Lévy (1999) destaca esta necessidade:

[...] o uso crescente das tecnologias digitais e das redes de comunicação interativa acompanha e amplifica uma profunda mutação na relação com o saber. Ao prolongar determinadas capacidades cognitivas humanas (memória, imaginação, percepção), as tecnologias intelectuais com suporte digital redefinem seu alcance. E algumas vezes até mesmo sua natureza. As novas possibilidades de criação coletiva distribuída, aprendizagem cooperativa e colaboração em rede oferecida pelo ciberespaço colocam novamente em questão o funcionamento das instituições e os modos habituais de divisão do trabalho, tanto na empresa como nas escolas. (LÉVY, 1999, p.98).

Formar um prosumidor é um processo infindável, implica em mudar as regras de como ensinar e aprender. Os caminhos não são dados, se constroem cooperativamente em comunidades de aprendizagem, com produções que se concretizam através do intenso envolvimento dos alunos e mediados pelo professor. Não existem perguntas para as respostas, essas precisam ser construídas. Isso implica em avanços, na busca constante por recursos educacionais que permitam a experimentação do processo de autoria.

Buscar um novo conhecimento também é a busca de novos métodos. "O método é o que ensina a aprender. É uma viagem que não se inicia com o método; inicia-se com a busca do método." (MORIN, CIURANA e MOTTA, 2003, p. 29). Esta busca pelo método também é a busca do conhecimento, é uma maneira de formar prosumidor.

Neste contexto "ser ensinante significa abrir um espaço para aprender, espaço objetivo-subjetivo em que se realizam dois trabalhos simultâneos: 1-construção de conhecimentos; 2-construção de si mesmo, como sujeito criativo e pensante" (FERNANDES, 2001, p. 30). Esse abrir espaços para o aprender pode ser o modo a tornarse um prosumidor. No educar pela autoria o professor, além de provocador de aprendizagens e crescimento dos alunos, assume a função de prosumidor junto com seus alunos, desafiando a todos para que também sejam colaboradores das aprendizagens de seus colegas. 
Trabalhar nas licenciaturas com ferramentas que permitam aos alunos aprender cooperativamente, sustentados pela tecnologia, implica em ações conjuntas de reconstrução de conteúdos previamente formulados, multiplicar as possibilidades de produções individuais e coletivas, além de impulsionar a autonomia.

Utilizar as TIC na escola implica intenso envolvimento com as ferramentas de autoria, constituindo a base de todo um processo. Mas a ferramenta em si não garante nada, é preciso envolver estudantes a aprender com elas, pois suas propriedades pedagógicas permitem formular novos conceitos, encontrar soluções e expressar novos conhecimentos, criando espaço para um novo aluno, aquele que consome e produz conhecimento, conectando aprendizagens da sala de aula com a realidade.

Para Demo (1997, p. 22), "a ciência é uma pretensão de conhecimento, dentro de um processo infindável de busca e pesquisa". Produzir seu próprio conhecimento nunca chega a um termo final, podendo os conhecimentos produzidos serem sempre submetidos a novos recursos pedagógicos e serem reconstruídos, desencadeando novas aprendizagens, o que é essencial na busca de formação de novos professores.

Ser prosumidor, além de proporcionar o crescimento e o envolvimento individual dos alunos, possibilita ações e interações coletivas, garantindo uma qualidade no processo de construção de competências e de reconstrução social.

O que muda é que tais autores não assomam no ambiente como proprietários de ideias, mas distribuidores de ideias com as quais contribuem abertamente sem apropriação individualista. Nisso, não se dilui o autor, mas comparece outro tipo de autor, aquele que é original não para si, mas para o grupo. (DEMO, 2009, p. 23)

Para que o prosumidor possa interagir com outros sujeitos, cada aluno precisa reconstruir seus próprios conhecimentos e teorias, assumindo a autoria nesse processo. Assumir-se autor é desenvolver um consumo crítico de recursos tecnológicos e produzir a partir dos mesmos.

Ser prosumidor conduz ao aprender a aprender, em consonância com um dos pilares ${ }^{1}$ para a educação do século XXI, exercitando um envolvimento ativo com as TIC. Mais do que assimilar conhecimentos, a autoria afeta, mais do que a quantidade, a qualidade das aprendizagens; o que inclui e enfatiza a qualidade política, "impulso crítico e criativo da educação emancipatória" (DEMO, 1997, p.16), o que está relacionado a intervir na realidade, não apenas reconstruindo conhecimentos, mas criando espaços de domínio de ferramentas digitais e possibilitando a capacidade de intervir e transformar as realidades.

\section{Resultados}

Conforme destacado, um dos pressupostos do projeto era que o público da licenciatura fosse de nativos digitais. Para aferir esse pressuposto, foi aplicado um questionário visando identificar que competências na manipulação de recursos de TIC os licenciandos tinham. O questionário era composto de 42 perguntas partindo de simples (saber ligar um computador) até aquelas voltadas para autoria (desenvolver páginas, construir blogs, editar áudio, etc.). Um vez tabuladas as respostas, foi possível classificar os licenciandos em 
níveis de inclusão digital. Ao contrário do que se esperava, dos 16 licenciandos 10 foram considerados como sem fluência digital, tendo apenas nível intermediário de conhecimento de recursos de TIC. Quatro deles foram considerados fluentes digitais e dois deles já considerados com conhecimento técnico suficiente para serem prosumidores.

Buscando compreender uma realidade distinta do que aquela suposta no início do projeto (nativos digitais com boa fluência digital), uma vez que a faixa etária dos licenciandos variava de 20 a 23 anos, analisamos o contexto sócio-econômico dos alunos. No contexto social, há que se considerar os dados de inclusão digital da região na qual está inserida a universidade que abriga o curso de licenciatura: apesar do Rio de Janeiro estar entre os estados mais incluídos do Brasil, há disparidades dentro do mesmo, particularmente na região Norte Fluminense. O Mapa da Exclusão Digital da Fundação Getúlio Vagas apontava para o município de Campos um índice de inclusão entre 6 e 13\% no início da década de $2000^{8}$. Já no que concerne a questão econômica, 11 dos 16 licenciandos trabalhavam até mesmo em atividades não relacionadas à docência para garantir condições financeiras de poder fazer um curso universitário em cidade distinta de sua origem familiar e não possuíam acesso a computador fora daqueles disponibilizados pela universidade.

Em princípio, a constatação da não fluência digital poderia ter dificultado o alcance da meta de tornar todo o grupo suficientemente fluente em termos digitais para explorar o potencial de autoria das TIC, mas a organização da proposta em níveis de interação, conforme ilustrado na Figura 2, e a presença de dois licenciandos com domínio de parte das ferramentas propostas facilitou o processo. Assim, os dois licenciandos com melhor domínio das ferramentas foram capacitados à parte, em oficinas intensivas, para depois atuarem como monitores junto à turma.

Após as oficinas com os monitores, foram organizadas oficinas para cada uma das ferramentas escolhidas. Em cada oficina foi desenvolvido um protótipo simples de material digital na área de Química, de livre escolha dos licenciandos. Os mesmos somente foram orientados a trabalhar sempre no mesmo tema, de modo que uma produção pudesse ser aproveitada na outra. Ao final das oficinas, os licenciandos, organizados em grupos, ministraram uma aula utilizando o material digital desenvolvido e outros materiais selecionados na Web em turma escolhida em escolas públicas do município de Campos.

Ao final de todo o processo, cada licenciando foi convidado a registrar um depoimento sobre seu percurso rumo à autoria, do qual alguns extratos foram retirados, conforme segue, visando ilustrar as diferentes percepções dos envolvidos no projeto.

Alguns extratos permitem destacar o potencial de compartilhamento propiciado pelas ferramentas, como o depoimento da Aluna A em relação ao Google Docs:

Gostei muito de ter trabalhado com esta ferramenta, pois compartilhar textos na internet facilita o trabalho de equipe. Esta ferramenta pode ser utilizada pelos professores para passar trabalhos em grupo no qual cada aluno contribuiria com uma parcela do texto. Como o professor pode verificar a contribuição de cada aluno, todos teriam que participar [grifos nossos].

\footnotetext{
${ }^{8}$ Apesar de algumas pesquisas como a TIC Domicílio, do CETIC, fornecerem dados mais recentes, não são por município.
} 
O Aluno B comentou:

[...] Na educação, creio eu, ser uma ferramenta interessante para estimular a criatividade e a escrita dos alunos [...]

Sobre o Wink ${ }^{9}$, a Aluna A complementa:

Esta ferramenta também está no ranking das que eu mais gostei. [...]. Na parte educativa, pode ser usada pelos professores para mostrarem aos alunos como se faz determinada atividade interativa, ou para mostrar como se usa determinado programa educativo, sem ter que dar uma aula na sala sobre isso. Economiza um bom tempo de aula, pois o professor leva o tutorial pronto [grifo nosso].

Com relação às aulas ministradas, usando o próprio material, destacamos o depoimento do Aluno C:

Eu gostei muito da aula e de ter dado a aula dessa forma. Foi meio desgastante preparar tudo [...] mas no final achei que foi compensador, achei muito bom mostrar aos alunos o vídeo que nós mesmos preparamos [grifo nosso] [...]. Pelo que foi observado os alunos em sua grande maioria gostaram da aula e assimilaram bem o conteúdo.

Essas declarações mostram que os alunos, ao experimentar o potencial de cada ferramenta, conseguem visualizar melhor como elas podem ser utilizadas em sala de aula e como contribuem para o trabalho do professor (a possibilidade de ter uma ferramenta que estimule a participação de todos - Google Docs - e a economia do tempo de aula - Wink).

A declaração do Aluno $\mathrm{C}$ reflete a importância do professor tornar-se um prosumidor. Além dos benefícios da valorização do professor, ao criar seu próprio conteúdo ele tem a possibilidade de adequar as necessidades de sua disciplina ao contexto de seus alunos. Dessa forma, o aproveitamento dos recursos é muito maior.

Um dos alunos que atuou como monitor, apesar de já conhecer as ferramentas, não havia pensado no seu próprio papel de autor:

Eu já sabia fazer o uso do movie [Windows Movie Maker], mas eu nunca pensei na hipótese de fazer uma edição e colocá-la em sala de aula. Mas só que o resultado do nosso vídeo foi um desastre, muito porque agente (sic) fez de última hora, mas depois agente (sic) fez outro vídeo o ficou muito melhor do que o outro. Essa atividade foi tão legal que na mesma semana eu fiz um vídeo e coloquei para os meus alunos assistirem e foi muito legal o resultado.

Outra aluna declara, sobre a aula dada por ela:

Os alunos ainda me pediram para dar mais aulas utilizando objetos! Fiquei feliz por eles terem gostado, mostra que a minha aula foi interessante e dinâmica, e o objeto deu grande contribuição para isso.

A análise da caminhada dos licenciandos buscando o domínio de ferramentas até a experimentação de uma aula usando material digital desenvolvido por eles próprios mostra que com o uso desses recursos é possível atingir diferentes níveis de participação e possibilitar aos alunos não somente o uso eficaz dos recursos existentes, como também a

\footnotetext{
${ }^{9}$ Software para criação de tutoriais.
} 
produção de recursos pedagógicos digitais. Essa mudança de simples consumidor para produtor permite a verdadeira inclusão digital, onde o indivíduo consegue utilizar diversos recursos na produção de conhecimento.

\section{Considerações finais}

Neste artigo relatamos um processo de formação de autores inserido no contexto de um curso de formação inicial de professores de Química. Partiu-se da hipótese de que os alunos do curso em questão, por serem nativos digitais, teriam facilidade no processo de tornarem-se autores. Além disso, pensou-se que estes teriam uma maior familiaridade com o uso das ferramentas, o que permitiria explorar as potencialidades das TICs atuais para que sejam também produtores e não apenas consumidores de conteúdo.

No entanto, a aplicação de um questionário para os licenciandos mostrou que parte da hipótese não se aplicava, uma vez que apesar de serem nativos digitais, vivendo numa sociedade imersa em inúmeros gadgets tecnológicos, a maior parte deles não tinha acesso a computadores fora da universidade e não dominava conhecimentos além de intermediários na manipulação de TICs. Esse foi, portanto, o principal obstáculo encontrado para a formação dos licenciandos enquanto prosumidores: a ausência de pré-requisitos no que concerne ao domínio da tecnologia. O segundo limite encontrado, decorrente da própria situação sócio-econômica dos licenciandos foi a dificuldade ou quase impossibilidade de usarem computadores fora da universidade. Ainda, a infra-estrutura desta tornou inviável aprofundar o processo de formação do grupo. Finalmente, a infra-estrutura das próprias escolas públicas: no processo de busca da autoria entre licenciandos, esperar-se-ia motivar os mesmos para que de alguma maneira estimulassem a autoria também entre seus alunos, mas as dificuldades encontradas para uso de material digital nas escolas do município mostraram ser esta uma meta um tanto quanto longínqua.

No entanto, em que pesem os limites, sobretudo de infra-estrutura, há que se destacar as possibilidades, na convergência do que Demo aponta como distribuidores de idéias. Se, por um lado, a velocidade de adoção das TIC em sala de aula não é a mesma de sua produção e utilização pelo mercado, essa discrepância torna fundamental sua inclusão nos currículos das universidades de todo país de modo a melhor qualificar os futuros profissionais da educação. Nesta proposta de curso, buscou-se oferecer aos alunos as ferramentas necessárias para que ele se tornasse, além de consumidor crítico de recursos educativos, um produtor dos mesmos.

Nossa experiência mostrou ainda que é possível capacitar estes professores e que o uso destas ferramentas durante sua formação os tornam aptos a utilizá-las da maneira mais adequada e criativa em sua vida profissional, aproveitando melhor o potencial de autoria das TIC. A superação das dificuldades de inclusão digital dos licenciandos levando-os ao perfil de possíveis autores melhora a própria visão deles sobre seu trabalho de futuros professores. 


\section{Referências}

ANDERSON, C. (2006). A cauda longa. Rio de Janeiro: Campus, 2006.

DEMO, P. Professor do futuro e reconstrução do conhecimento. Petrópolis, RJ: Vozes, 2004.

FAGUNDES, L. (2004), Podemos vencer a exclusão digital, Entrevista, 2004. Disponível em http://revistaescola.abril.com.br/politicas-publicas/planejamento-efinanciamento/podemos-vencer-exclusao-digital-425469.shtml. Acesso 20 ago. 2008.

FERNANDES, A. O saber em jogo: a psicopedagogia propiciando autorias de pensamento. Porto Alege: Artmed, 2001.

LÉVY, P. As tecnologias da inteligência. Rio de Janeiro: Ed. 34, 1993.

LÉVY, P. Cibercultura. São Paulo: Editora 34, 1999.

MATTOS, F. A. M. (2003), Exclusão digital e exclusão social: elementos para uma discussão, Transinformação, Campinas, $\mathrm{n}^{\circ}$ 15, 2003.

MORIN E. Os Sete Saberes necessários à Educação do Futuro. São Paulo: Cortez; Brasília, UNESCO, 2002.

MORIN, E.; CIURANA, E. R.; MOTTA, R. D. Educar na era planetária. São Paulo: Cortez, 2003.

O'REILLY, T. (2005) What Is Web 2.0: Design Patterns and Business Models for the Next Generation of Software. O'Reilly Publishing, 2005.

PAPERT, S.; RESNICK, M. Technological Fluency and the Representation of Knowledge. Proposal to the National Science Foundation. MIT MediaLab, 1995

PRENSKY, M. Digital natives, digital immigrants. On the Horizon, MCB University Press, v.9, n. 5, out. 2001. Disponível em: $<$ http://www.marcprensky.com/writing/Prensky\%20-

$\%$ 20Digital\%20Natives,\%20Digital\%20Immigrants\%20-\%20Part1.pdf $>$ Acesso em: 10 ago. 2010.

SILVA, M. Sala de aula interativa. Rio de Janeiro: Quarter, 2002.

TAPSCOTT, D.; WILLIAMS, A. Wikinomics: como a colaboração em massa pode mudar o seu negócio. (Tradução de Marcello Lino). Rio de Janeiro: Nova Fronteira, 2007.

THIOLlENT, M. Metodologia da Pesquisa-Ação - 15. ed. São Paulo: Cortez, 2007. (Coleção Temas Básicos de Pesquisa-Ação)

TOFFLER, A. A terceira onda. Rio de Janeiro: Record, 2007. 